\title{
Linkage of a Membrane Skeleton to Integral Membrane Glycoproteins in Human Platelets \\ Identification of One of the Glycoproteins as Glycoprotein Ib
}

Joan E. B. Fox

Gladstone Foundation Laboratories for Cardiovascular Disease, Department of Pathology, Cardiovascular Research Institute, University of California, San Francisco, California 94140-0608

\begin{abstract}
Experiments were performed to determine whether platelets contain a membrane skeleton. Platelets were labeled by a sodium periodate/sodium $\left[{ }^{3} \mathrm{H}\right]$ borohydride method and lysed with Triton $\mathrm{X}-100$. Much of the filamentous actin could be sedimented at low $\mathrm{g}$ forces $(15,600 \mathrm{~g}, 4 \mathrm{~min})$, but some of the actin filaments required high-speed centrifugation for their sedimentation $(100,000 \mathrm{~g}, 3 \mathrm{~h})$. The latter filaments differed from those in the low-speed pellet in that they could not be depolymerized by $\mathrm{Ca}^{2+}$ and could not be sedimented at low $g$ forces even from Triton $\mathrm{X}-100$ lysates of platelets that had been activated with thrombin. Actin-binding protein sedimented with both types of filaments, but ${ }^{3} \mathrm{H}$-labeled membrane glycoproteins were recovered mainly with the high-speed filaments. The primary ${ }^{3} \mathrm{H}$-labeled glycoprotein recovered with this "membrane skeleton" was glycoprotein (GP) Ib. Approximately $70 \%$ of the platelet GP Ib was present in this skeleton. Several other minor glycoproteins, including $>\mathbf{5 0} \%$ of the GP Ia and small amounts of three unidentified glycoproteins of $M_{r}>200,000$, were also recovered with the membrane skeleton. The Triton X-100 insolubility of GP Ib, GP Ia, a minor membrane glycoprotein of $250,000 M_{\mathrm{r}}$, and actinbinding protein resulted from their association with actin filaments as they were rendered Triton $\mathrm{X}$-100-soluble when actin filaments were depolymerized with deoxyribonuclease $I$ and coisolated with actin filaments on sucrose gradients. When isolated platelet plasma membranes were extracted with Triton $X-100$, actin, actin-binding protein, and GP Ib were recovered as the Triton X-100 residue. These studies show that unstimulated platelets contain a membrane skeleton composed of actin filaments and actin-binding protein that is distinct from the rest of the cytoskeleton and is attached to GP Ib, GP Ia, and a minor glycoprotein of $250,000 M_{\mathrm{r}}$ on the plasma membrane.

\section{Introduction}

Unstimulated platelets have a characteristic discoid shape that is thought to be maintained at least in part by the coil of microtubules within platelets $(1,2)$. However, platelets also contain much actin (3), $\sim 40 \%$ of which is filamentous in unstimulated platelets $(4,5)$. By analogy to the erythrocyte, these filaments could act as a skeleton stabilizing the shape of the cell (6). Evidence for such a possibility comes from the morphologic dem-

Portions of this work have been published as an abstract (1983. Blood. 62:255).

Address reprint requests to Dr. Fox, Gladstone Foundation Laboratories, P.O. Box 40608, San Francisco, CA 94140-0608.

Received for publication 15 October 1984 and in revised form 26 March 1985.

J. Clin. Invest.

(C) The American Society for Clinical Investigation, Inc.

$0021-9738 / 85 / 10 / 1673 / 11 \$ 1.00$

Volume 76, October 1985, 1673-1683 onstration that actin filaments in unstimulated platelets are concentrated just beneath the plasma membrane ${ }^{1}(4)$ and can be isolated from Triton X-100-lysed platelets as structures that maintain the discoid shape of the unextracted cell. ${ }^{2}$ Further evidence for a role of actin filaments comes from recent studies showing that cytochalasin B lowers the resistance of platelets to deformation (2) and that actin coisolates with platelet plasma membranes $(7,8)$. For a submembranous actin filament skeleton to be important in regulating the shape of platelets, it would have to be attached to the plasma membrane. Despite the obvious importance of actin filament-membrane interactions in the functions of platelets and other cell types $(5,6)$, little is known about the molecular nature of the interaction between actin filaments and plasma membranes in any cell type. One exception to this generalization is the characterization of actin filamentmembrane interactions in erythrocyte membranes (9). Although glycoprotein (GP) ${ }^{3}$ IIb and GP IIIa have been implicated as attachment sites in activated platelets (10), nothing is known about attachment sites in unstimulated platelets.

The present report shows that platelets contain a membrane skeleton that is distinct from the rest of the cytoskeleton. The major components of the membrane skeleton are actin and actinbinding protein. It is attached to GP Ib, GP Ia, and a $M_{\mathrm{r}}$ $=250,000$ glycoprotein of the plasma membrane.

\section{Methods}

Isolation and surface labeling of platelet suspensions. The venous blood of healthy adult donors was collected into acid citrate/dextrose, and the platelet-rich plasma was obtained (11). Platelets were isolated by a centrifugation procedure as described previously (4). Platelet-rich plasma was centrifuged at $730 \mathrm{~g}$ for $15 \mathrm{~min}$, and the platelet pellet was washed two times in a buffer containing $120 \mathrm{mM}$ sodium chloride, $13 \mathrm{mM}$ tri-

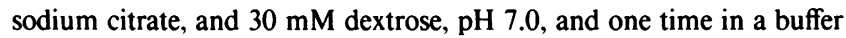
containing $154 \mathrm{mM}$ sodium chloride, $10 \mathrm{mM}$ Tris- $\mathrm{HCl}$, and $1 \mathrm{mM}$ EDTA, $\mathrm{pH}$ 7.4. Platelets were finally resuspended at a concentration of $1 \times 10^{9}$ platelets $/ \mathrm{ml}$ in Tyrode's buffer containing $138 \mathrm{mM}$ sodium chloride, $2.9 \mathrm{mM}$ potassium chloride, $12 \mathrm{mM}$ sodium bicarbonate, $0.36 \mathrm{mM}$ sodium phosphate, $5.5 \mathrm{mM}$ glucose, $1.8 \mathrm{mM}$ calcium chloride, and 0.4 $\mathrm{mM}$ magnesium chloride, $\mathrm{pH}$ 7.4.

Various modifications of this general centrifugation procedure were employed depending upon the experiments to be performed. To obtain unstimulated discoid cells, prostacyclin (Sigma Chemical Co., St. Louis, $\mathrm{MO}$ ) was included in the anticoagulant $(50 \mathrm{ng} / \mathrm{ml})$ and in all the washing buffers $(10 \mathrm{ng} / \mathrm{ml})$, which were preequilibrated at $37^{\circ} \mathrm{C}$ before use. Platelets were suspended in Tyrode's buffer that contained $10 \mathrm{ng} / \mathrm{ml}$ prosta-

1. Fox, J. E. B., and J. Boyles. 1985. Platelets contain a membrane skeleton linked to plasma membrane glycoproteins through actin-binding protein. J. Cell Biol. In press. (Abstr.)

2. Boyles J., J. E. B. Fox, D. R. Phillips, and P. Stenberg. 1985. Organization of the cytoskeleton in resting, discoid platelets: preservation of actin filaments by a modified fixation that prevents osmium damage. $J$. Cell Biol. In press.

3. Abbreviation used in this paper: GP, glycoprotein. 
cyclin and were incubated in this buffer at $37^{\circ} \mathrm{C}$ for at least $60 \mathrm{~min}$ before experiments were initiated (4). To obtain platelets in which the discoid shape was lost and the majority of the preexisting actin filaments were cross-linked into networks that could be sedimented at low $g$ forces from Triton X-100-lysed platelets, platelets were isolated at ambient temperatures in the absence of prostacyclin (4). Final platelet suspensions were resuspended at ambient temperatures in the absence of prostacyclin, and experiments were initiated immediately. For labeling by the sodium metaperiodate/sodium $\left[{ }^{3} \mathrm{H}\right]$ borohydride method, platelets isolated in the presence of prostacyclin were resuspended at $1 \times 10^{9}$ platelets $/ \mathrm{ml}$ in a buffer containing $150 \mathrm{mM}$ sodium chloride, $1 \mathrm{mM}$ EDTA, and $10 \mathrm{mM}$ Hepes, pH 7.6 and labeled as described by Berndt and Phillips (12) except that all buffers contained $10 \mathrm{ng} / \mathrm{ml}$ prostacyclin which was added just before use. Labeled platelets were finally resuspended in Tyrode's buffer containing $10 \mathrm{ng} / \mathrm{ml}$ prostacyclin and incubated at $37^{\circ} \mathrm{C}$ for at least 60 min before use. When platelets were to be subsequently activated by addition of a platelet agonist, prostacyclin was omitted from the Tyrode's buffer. Platelet counts were determined with a Coulter counter (Coulter Electronics, Inc., Hialeah, FL).

Isolation and analysis of actin filaments and associated proteins. Platelets were lysed by addition of an equal volume of buffer containing 2\% Triton X-100 (Sigma Chemical Co.), 100 mM Tris-HCl, pH 7.4 and, where indicated, $10 \mathrm{mM}$ EGTA to chelate $\mathrm{Ca}^{2+}, 2 \mathrm{mg} / \mathrm{ml}$ leupeptin (Vega Biotechnologies, Tucson, $\mathrm{AZ}$ ) to inhibit activity of the $\mathrm{Ca}^{2+}$-dependent protease or $2 \mathrm{mg} / \mathrm{ml}$ DNase I (beef pancreas, Boehringer Mannheim, Chicago, IL) (treated with $100 \mathrm{mM}$ benzamidine and $2 \mathrm{mM}$ phenylmethylsulfonyl fluoride) to depolymerize actin filaments. In some experiments, as indicated, platelets were suspended in Tyrode's buffer without added divalent cations and containing 1 mM EDTA, pH 7.4 and activated with $0.1 \mathrm{NIH} \mathrm{U}$ of thrombin/ml before lysis. Triton X100 -soluble and -insoluble fractions were separated by centrifugation at $4^{\circ} \mathrm{C}$ either for $4 \mathrm{~min}$ at $15,600 \mathrm{~g}$ or for $3 \mathrm{~h}$ at $100,000 \mathrm{~g}$. Fractions were analyzed on SDS-polyacrylamide gels by the method of Laemmli (13) as described previously (14), on two-dimensional nonreduced-reduced gels by the method of Phillips and Agin (15), or on two-dimensional gels by the method of O'Farrell (16) as described previously (17). The relative amounts of actin in the fractions were determined by densitometric scans of SDS-polyacrylamide gels (14). The relative amounts of radioactivity in ${ }^{3} \mathrm{H}$-labeled glycoproteins were determined by fluorography of gels treated with EN $^{3} \mathrm{HANCE}$ (New England Nuclear, Boston, MA) and quantitated by liquid scintillation counting of the areas of dried gels that superimposed with the bands of interest on the processed fluorograms (14). Glycoproteins in fractions obtained from unlabeled platelets were detected by the periodic acid-Schiff's staining technique (18) or by incubating Western blots, obtained by the method of Towbin et al. (19), with antibodies against the glycoproteins of interest. Molecular weights were estimated by calibration of the gels with molecular weight markers (Bio-Rad Laboratories, Richmond, CA).

Analysis of platelet lysates by sucrose density gradient centrifugation. Platelets were lysed by addition of an equal volume of Tyrode's buffer containing 2\% Triton X-100 (Sigma Chemical Co.) and, where indicated, $2 \mathrm{mg} / \mathrm{ml}$ leupeptin (Vega Biotechnologies). Lysates were centrifuged at $15,600 \mathrm{~g}$ for $4 \mathrm{~min}$, and $200 \mu \mathrm{l}$ of the supernatant was applied to a linear $5-25 \%$ sucrose gradient (volume $=5.0-5.2 \mathrm{ml}$ ) prepared in a buffer containing $2 \mathrm{mM}$ calcium chloride, $0.2 \%$ Triton X-100, $1 \mathrm{mg} / \mathrm{ml}$ leupeptin, and $100 \mathrm{mM}$ Tris- $\mathrm{HCl}, \mathrm{pH}$ 7.4. Gradients were centrifuged in a SW55 rotor (Beckman Instruments, Inc., Spinco Div., Palo Alto, CA) using the integrator on a Beckman L8-70 ultracentrifuge set at $w^{2} t=5.92$ $\times 10^{11}(\sim 5 \mathrm{~h}$ at $55,000 \mathrm{rpm}, 390,000 \mathrm{~g})$. The gradients were fractionated into 16-17 fractions from the bottom of the tubes, and the fractions were solubilized in an SDS-containing buffer for analysis on SDS-polyacrylamide gels. Sedimentation coefficients were determined as described by Martin and Ames (20). The following proteins were used for calibration: catalase, $S_{20, w}=11.30$ (Boehringer Mannheim); $\gamma$-globulin, $S_{20, w}$ $=7.12$ (Sigma Chemical Co.); lactoperoxidase, $S_{20, w}=5.37$ (a gift from Dr. Martin Morrison, St. Jude Hospital, Memphis, TN); bovine serum albumin, $S_{20, w}=4.60$ (Sigma Chemical Co.); ovalbumin, $S_{20, w}=3.66$ (Sigma Chemical Co.). Bovine serum albumin iodinated by the Iodobead method (21) and catalase iodinated by the Bolton-Hunter method
(22) were included as internal standards in each sucrose gradient to relate separate runs of platelet lysates to the reference proteins. All steps were performed at ambient temperatures.

Isolation and Triton X-100 extraction of platelet membranes. Platelet membranes were isolated from freshly drawn blood by a modification of the method described by Jennings and Phillips (23). Briefly, washed platelets were suspended at a concentration of $4 \times 10^{9}$ platelets $/ \mathrm{ml}$ in an ice-cold buffer containing $150 \mathrm{mM}$ sodium chloride, $50 \mathrm{mM}$ calcium chloride, $2 \mathrm{mg} / \mathrm{ml}$ leupeptin, $50 \mathrm{mM}$ benzamidine (Sigma Chemical Co.), $1 \mathrm{mM}$ phenylmethylsulfonyl fluoride, and $20 \mathrm{mM}$ Tris- $\mathrm{HCl}, \mathrm{pH} 7.4$, and sonicated at $4^{\circ} \mathrm{C}$ in $1-\mathrm{ml}$ volumes four times for $10 \mathrm{~s}$ at 15 -s intervals using a Branson Sonifier Cell Disruptor 200 (Danbury, CT) at output control setting 4 . The sonicate was layered over an equal volume of $27 \%$ sucrose in the same buffer as the platelets (except that the leupeptin concentration was $1 \mathrm{mg} / \mathrm{ml}$ ) and centrifuged for $3 \mathrm{~h}$ at $140,000 \mathrm{~g}$. Membranes were recovered from the interface between the sucrose solution and the sonicate, diluted 10 -fold (vol/vol) with $150 \mathrm{mM}$ sodium chloride, $50 \mathrm{mM}$ calcium chloride, $1 \mathrm{mg} / \mathrm{ml}$ leupeptin, $50 \mathrm{mM}$ benzamidine, 1 $\mathrm{mM}$ phenylmethylsulfonyl fluoride, and $20 \mathrm{mM}$ Tris- $\mathrm{HCl}, \mathrm{pH} 7.4$ and centrifuged at $80,000 \mathrm{~g}$ for $1 \mathrm{~h}$ at $4^{\circ} \mathrm{C}$. The membrane pellet was resuspended at $4^{\circ} \mathrm{C}$ in the original platelet volume of the same buffer using a glass homogenizer to facilitate resuspension and extracted with Triton X-100 by addition of an equal volume of an ice-cold buffer containing $2 \%$ Triton X-100, $10 \mathrm{mM}$ EGTA, $2 \mathrm{mg} / \mathrm{ml}$ leupeptin, $100 \mathrm{mM}$ benzamidine, $2 \mathrm{mM}$ phenylmethylsulfonyl fluoride, and $100 \mathrm{mM}$ Tris- $\mathrm{HCl}, \mathrm{pH}$ 7.4. Triton $\mathrm{X}-100$-insoluble and -soluble fractions were separated by centrifugation for $3 \mathrm{~h}$ at $100,000 \mathrm{~g}$.

Purification of platelet proteins. GP Ib was extracted from fresh human platelets using the Triton X-114-containing lysis buffer described by Newman et al. (24). GP Ib, detected by periodic acid-Schiff's staining (18) of SDS-polyacrylamide gels, was recovered in the aqueous phase. This solution was treated with ice-cold Triton X-100 (1\%, final concentration) and applied at a flow rate of $10 \mathrm{ml} / \mathrm{h}$ to an affinity column (1.5$\mathrm{ml}$ bed volume) of wheat germ lectin coupled to Sepharose 6MB (Sigma Chemical Co.), previously equilibrated in a buffer containing $2.5 \mathrm{mM}$ EDTA, $50 \mathrm{mM}$ sodium chloride, $1 \%$ Triton $\mathrm{X}-100$, and $50 \mathrm{mM}$ Hepes, $\mathrm{pH}$ 7.4. The column was washed extensively with this same buffer, then with a buffer containing $1 \mathrm{mM}$ EDTA, $0.1 \%$ Triton X-100, and $10 \mathrm{mM}$

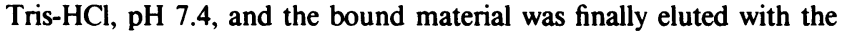
latter buffer containing $0.25 \mathrm{M} \mathrm{N}$-acetyl glucosamine (Sigma Chemical Co.). Fractions of $1.35 \mathrm{ml}$ were collected, and those containing GP Ib were applied to a column $(2.5 \times 0.7 \mathrm{~cm})$ of DEAE-cellulose (Whatman Chemical Separation, Inc., Clifton, NJ), previously equilibrated in $1 \mathrm{mM}$ EDTA, $0.1 \%$ Triton $\mathrm{X}-100$, and $10 \mathrm{mM}$ Tris- $\mathrm{HCl}, \mathrm{pH} 7.4$, at a flow rate of $15 \mathrm{ml} / \mathrm{h}$. The column was washed and then eluted with a $120-\mathrm{ml}$ linear gradient of $0-500 \mathrm{mM}$ sodium chloride. GP Ib eluted toward the middle of the gradient. The purified glycoprotein was homogeneous when stained by the periodic acid-Schiff's reagent; however, a sensitive silver stain (25) revealed the presence of 9 or 10 minor contaminants that were estimated, between them, to account for about $10 \%$ of the total protein.

Glycocalicin was obtained by a modification of the method of Okumura et al. (26) as developed by J. W. Lawler (personal communication). Briefly, platelets from fresh platelet concentrates (Peninsula Memorial Blood Bank, Burlingame, CA) were washed and resuspended in $1.0 \mathrm{M}$ sodium chloride, $1 \mathrm{mM}$ EDTA, and $20 \mathrm{mM}$ Tris- $\mathrm{HCl}, \mathrm{pH}$ 7.6. The suspension was stirred at $22^{\circ} \mathrm{C}$ for $1 \mathrm{~h}$ and then centrifuged at $50,000 \mathrm{~g}$ for $1 \mathrm{~h}$ at $4^{\circ} \mathrm{C}$. The supernatant was dialyzed into a buffer containing $150 \mathrm{mM}$ sodium chloride, $1 \mathrm{mM}$ EDTA, and $20 \mathrm{mM}$ Tris- $\mathrm{HCl}$, pH 7.6 and applied to a column of wheat germ agglutinin coupled to Sepharose 6MB (Pharmacia Fine Chemicals, Piscataway, NJ). The column was washed with the same buffer containing $4.5 \mathrm{mM} \mathrm{N}$-acetyl glucosamine (Sigma Chemical Co.) and then with the same buffer containing $\mathbf{4 5 0}$ $\mathrm{mM} N$-acetyl glucosamine to elute glycocalicin. Glycocalicin was then further purified by hydroxylapatite chromatography (26).

Actin-binding protein was purified from fresh human platelet concentrates as described previously (27). $\mathrm{Ca}^{2+}$-dependent protease was purified from fresh human platelet concentrates (27) and dialyzed into a buffer containing $5 \mathrm{mM}$ EDTA, $100 \mathrm{mM}$ potassium chloride, $5 \mathrm{mM}$ dithiothreitol, $0.02 \%$ sodium azide, and $50 \mathrm{mM}$ Hepes, $\mathrm{pH}$ 7.4. 
Antibody production and characterization. For generation of antibodies against glycocalicin, purified glycocalicin was electrophoresed through a 5\% SDS-polyacrylamide gel. Protein was visualized by brief ( $\sim 5$ min) staining with Coomassie brilliant blue and cut out of the gel in a narrow strip. The strip was neutralized by two 15 -min washes in $500 \mathrm{ml}$ of $50 \mathrm{mM}$ Tris- $\mathrm{HCl}, \mathrm{pH} 7.8$, homogenized with a Teflon homogenizer in $12 \mathrm{ml}$ of the same buffer, and stored at $-20^{\circ} \mathrm{C}$. Antibodies were raised by injection of the homogenized gels into rabbits by standard procedures as described previously (27). Antiserum was isolated by centrifugation of clotted blood for $20 \mathrm{~min}$ at $30,000 \mathrm{~g}$. The IgG fraction was obtained by precipitation at $4^{\circ} \mathrm{C}$ with $40 \%$ ammonium sulfate. Antibody against GP IIb and GP IIIa was a generous gift from Dr. Laurence Fitzgerald of the Gladstone Foundation Laboratories for Cardiovascular Disease, San Francisco. Antibodies against actin-binding protein and P235 were raised and characterized as described previously (27). Rabbit anti-chick actin was purchased from Miles-Yeda (Elkhart, IN).

The specificity of antibodies was confirmed using the immunoblot technique of Towbin et al. (19). Platelet protein was first electrophoresed through SDS-polyacrylamide gels containing $7.5 \%$ acrylamide in the resolving gel. Polypeptides were then transferred electrophoretically to nitrocellulose paper, which was incubated with antibodies and then with ${ }^{125}$ I-labeled Protein A (purchased from Sigma Chemical Co. and radiolabeled by the Iodo-bead method [21]). Binding of Protein A to antibodyantigen complexes was detected by autoradiography.

\section{Results}

Triton X-100 insolubility of ${ }^{3} \mathrm{H}$-labeled glycoproteins. Triton X100 solubilizes most platelet proteins but does not solubilize actin filaments and other proteins that are Triton X-100-insoluble because of their filament association (28). To determine whether any membrane glycoproteins were associated with actin filaments, the filaments were isolated by high-speed centrifugation $(100,000 \mathrm{~g}$ for $3 \mathrm{~h}$ ) from Triton X-100-lysed platelets in which the surface glycoproteins had been labeled by the sodium periodate/sodium $\left[{ }^{3} \mathrm{H}\right]$ borohydride method. As shown in Fig. 1 , several ${ }^{3} \mathrm{H}$-labeled glycoproteins were recovered in the Triton $\mathrm{X}-100$-insoluble fraction. Their recovery was selective in that other ${ }^{3} \mathrm{H}$-labeled glycoproteins were recovered totally in the Triton X-100-soluble fraction. Much of the major ${ }^{3} \mathrm{H}$-labeled glycoprotein, GP Ib, was recovered in the Triton X-100-insoluble fraction. Several criteria were used to confirm that this major ${ }^{3} \mathrm{H}$-labeled glycoprotein was GP Ib. First, it migrated further into SDS-polyacrylamide gels when reduced (Fig. $1 A$ ) than when not reduced (Fig. $1 B$ ). Calibration of the gels with molecular weight markers showed that it had a $M_{\mathrm{r}}$ of 146,000 when reduced and one of 166,000 when not reduced; these values are in good agreement with those previously reported for GP $\mathrm{Ib}_{\alpha}\left(M_{\mathrm{r}}\right.$ $=145,000)$ and the whole GP Ib molecule $\left(M_{\mathrm{r}}=160,000\right)$, respectively (29). Second, on two-dimensional nonreduced-reduced gels, the glycoprotein migrated off the diagonal line created by the majority of the platelet proteins in a position that was characteristic of GP Ib $(15,29)$ (Fig. 2). Third, this glycoprotein had a broad isoelectric point (pI) on two-dimensional gels prepared by the method of O'Farrell (16); this ranged from pI 6 to pI 8 (data not shown), a range that is similar to that reported previously for GP Ib $(29,30)$. Fourth, it reacted with monospecific antibodies raised against glycocalicin, the product of hydrolysis of GP Ib by the $\mathrm{Ca}^{2+}$-dependent protease (31) (Fig. 3).

In addition to GP Ib, other glycoproteins were also selectively recovered in varying amounts in the high-speed Triton X-100insoluble fraction (Figs. 1 and 2). Five of these were tentatively identified on nonreduced-reduced two-dimensional gels as GP Ia, GP IIa, GP IIb, GP IIIa, and GP IV (Fig. 2). The identity of

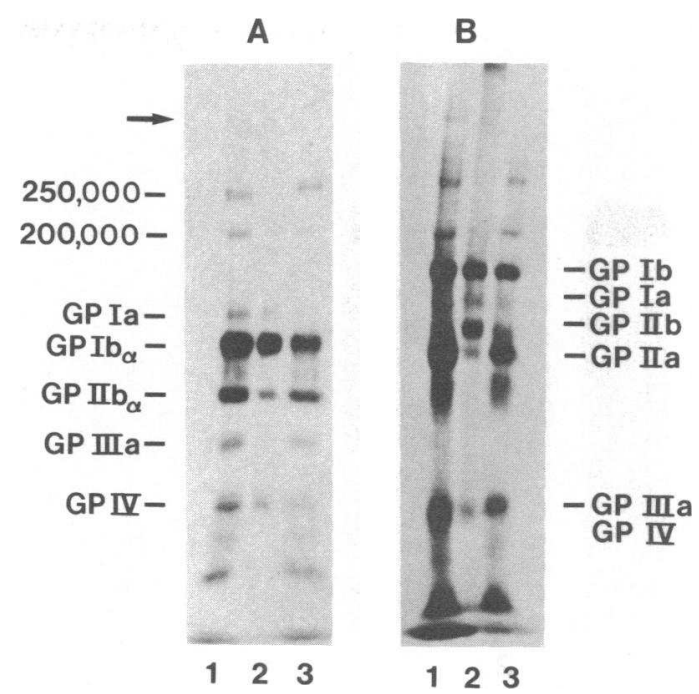

Figure 1. Recovery of ${ }^{3} \mathrm{H}$-labeled glycoproteins with Triton X-100-insoluble actin filaments. Platelets, surface-labeled by the sodium metaperiodate/sodium $\left[{ }^{3} \mathrm{H}\right]$ borohydride method, were suspended at 1 $\times 10^{9}$ platelets $/ \mathrm{ml}$ in Tyrode's solution and solubilized directly into an SDS-containing buffer (lane 1 ) or lysed by addition of an equal volume of an ice-cold buffer containing $2 \%$ Triton X-100, $10 \mathrm{mM}$ EGTA, $2 \mathrm{mg} / \mathrm{ml}$ leupeptin, and $100 \mathrm{mM}$ Tris- $\mathrm{HCl}, \mathrm{pH}$ 7.4. Lysates were centrifuged for $3 \mathrm{~h}$ at $100,000 \mathrm{~g}$ and the Triton X-100-insoluble (lane 2) and -soluble (lane 3) fractions solubilized in SDS. The contents of the ${ }^{3} \mathrm{H}$-labeled glycoproteins were analyzed by fluorography after SDS-polyacrylamide gel electrophoresis on $5 \%$ gel. $(A)$ Reduced buffer; $(B)$ nonreduced.

GP IIb and GP IIIa was confirmed on immunoblots using polyclonal antibodies specific for these glycoproteins (data not shown). Two additional glycoproteins that were often present in the high-speed Triton X-100-insoluble fraction from ${ }^{3} \mathrm{H}$-labeled platelets were identified only on the basis of their molecular weights $\left(M_{\mathrm{r}} \sim 250,000\right.$ and 200,000$)$ (Fig. 1). Yet another had an even higher molecular weight and has been labeled in Fig. 1 with an arrow. These latter three glycoproteins were minor ${ }^{3} \mathrm{H}-$ labeled glycoproteins and could only be detected upon long exposure of gels.

Quantitation of the amount of GP Ib showed that $70.2 \pm 4.4 \%$ (mean \pm standard error, $n=3$ ) was Triton X-100-insoluble. The remaining GP Ib was quantitatively recovered in the Triton X-
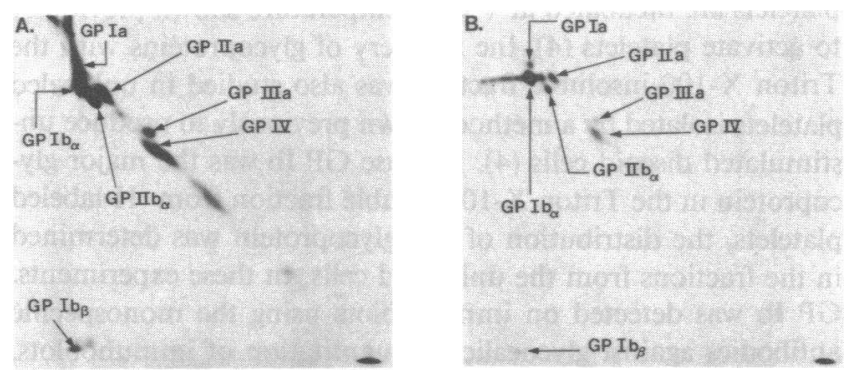

Figure 2. Nonreduced-reduced two-dimensional gels of ${ }^{3} \mathrm{H}$-labeled platelet proteins. Total ${ }^{3} \mathrm{H}$-labeled platelets $(A)$ or the Triton X-100insoluble fraction $(B)$, isolated as described in the legend to Fig. 1, were solubilized in an SDS buffer in the absence of reducing agents. The nonreduced samples were electrophoresed in the first dimension on $7.5 \%$ SDS-polyacrylamide gels, reduced, and electrophoresed in the second dimension, again on gels of $7.5 \%$ acrylamide. 


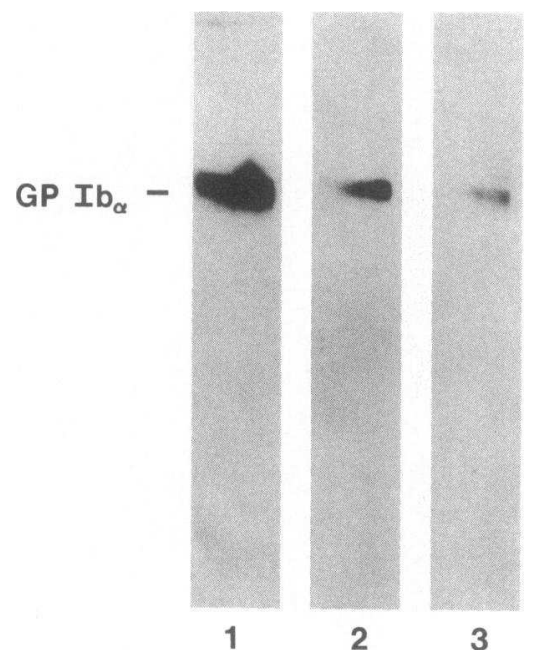

Figure 3. Recovery of GP Ib with the Triton X-100-insoluble actin filaments from unstimulated, discoid platelets. Platelets were isolated from plasma by a method shown previously to produce unstimulated, discoid cells (4). Platelets were solubilized directly into an SDS-containing buffer (lane 1 ) or lysed in Triton X-100, and the Triton X-100insoluble (lane 2) and -soluble fractions (lane 3) were isolated and solubilized in SDS as described in the legend to Fig. 1. Solubilized proteins were electrophoresed on $7.5 \%$ SDS-polyacrylamide gels and transferred to nitrocellulose paper by the method of Towbin et al. (19), and GP Ib was detected by incubation of the nitrocellulose paper with antibody against GP Ib and then with ${ }^{125} \mathrm{I}$-labeled Protein A. Antibody-antigen complexes were detected by autoradiography.

100 -soluble fraction. GP la appeared to be $>50 \%$ Triton X-100insoluble. The remaining filament-associated glycoproteins (GP IIa, GP IIb, GP IIIa, GP IV, and the three minor ones of $M_{\mathrm{r}}$ $>200,000$ ) were present in the Triton X-100-insoluble fraction in variable and usually quite small amounts. GP IV differed from the other glycoproteins in that its Triton X-100 insolubility was temperature-dependent. While similar amounts of most of the ${ }^{3} \mathrm{H}$-labeled glycoproteins were recovered in the Triton $\mathrm{X}$ 100 -insoluble fraction at $4^{\circ} \mathrm{C}$ and at ambient temperatures, recovery of GP IV in this fraction only occurred when buffers were employed at the lower temperature (Figs. 1 and 2 compared with subsequent figures).

Because the sodium periodate/sodium $\left[{ }^{3} \mathrm{H}\right]$ borohydride procedure for surface-labeling platelets includes a step at which platelets are incubated at $4^{\circ} \mathrm{C}$, a temperature shown previously to activate platelets (4), the recovery of glycoproteins with the Triton X-100-insoluble fraction was also studied in unlabeled platelets isolated by a method shown previously to produce unstimulated discoid cells (4). Because GP Ib was the major glycoprotein in the Triton X-100-soluble fraction from ${ }^{3} \mathrm{H}$-labeled platelets, the distribution of this glycoprotein was determined in the fractions from the unlabeled cells. In these experiments, GP Ib was detected on immunoblots using the monospecific antibodies against glycocalicin. Quantitation of immunoblots, performed by gamma counting of the region of nitrocellulose that corresponded to the position of GP Ib on the autoradiogram, confirmed that the results were linear with respect to the concentration of GP Ib (data not shown). The detection of GP Ib on immunoblots in these experiments also removed the potential problem of only a small pool of GP Ib being ${ }^{3} \mathrm{H}$-labeled by the sodium periodate/sodium $\left[{ }^{3} \mathrm{H}\right]$ borohydride method. Fig. 3 shows that the distribution of GP Ib between the Triton X-100-insoluble and -soluble fractions from unlabeled discoid platelets was similar to that in ${ }^{3} \mathrm{H}$-labeled platelets. The selective recovery of GP Ib in the Triton X-100-insoluble fraction from unlabeled platelets was confirmed using nonreduced-reduced two-dimensional gels on which GP Ib was detected as the major periodic acid-Schiff's staining protein on gels that were subsequently stained with Coomassie blue to visualize the diagonal obtained by the majority of the platelet proteins (data not shown). This method also showed that $>50 \%$ GP Ia was present in the high-speed Triton X-100-insoluble fraction. In contrast, GP IIb and GP IIIa from the unlabeled discoid cells appeared to be recovered almost entirely in the Triton X-100-soluble fraction, a conclusion that was supported on immunoblots using antibodies against these glycoproteins (data not shown).

Relationship between actin filament content and Triton $X$ 100 insolubility of ${ }^{3} \mathrm{H}$-labeled glycoproteins. The presence of ${ }^{3} \mathrm{H}$ labeled glycoproteins in the high-speed Triton X-100-insoluble fraction could have resulted from the association of these glycoproteins with actin filaments or from their inherent Triton X100 insolubility. To distinguish between these possibilities, actin filaments were depolymerized, and the effect of this on the solubility of GP Ib was examined. Two methods were used to depolymerize actin. In the first, filaments were depolymerized by the addition of DNase I to the lysis buffer (32). In the second, $\mathrm{Ca}^{2+}$ was added to the lysis buffer to induce the $\mathrm{Ca}^{2+}$-dependent depolymerization of filaments by gelsolin $(33,34)$.

Inclusion of DNase I in the lysis buffer caused depolymerization of $39.6 \pm 3.6 \%$ (mean $\pm \mathrm{SE}, n=3)$ of the actin filaments (Table I). The extent of depolymerization was greater $(54.9 \pm 6.0 \%)$ when DNase I was added in the presence of $\mathrm{Ca}^{2+}$, a result that is consistent with the known stimulatory effect of $\mathrm{Ca}^{2+}$ on DNase I $(32,35)$. Fig. 4 shows the effect of DNase I on the polypeptides cosedimenting with actin filaments. As seen in this figure, many other Coomassie brilliant blue-stained polypeptides were present in the high-speed sediment. The major ones were actin-binding protein and P235 (identified on immunoblots, data not shown), and myosin heavy chain (14). The only other one that was identified was $\alpha$-actinin (36). Comparison of the Triton X-100-insoluble and -soluble fractions (Fig. 4)

Table I. Effect of Depolymerization of Actin Filaments on the Recovery of GP Ib in Triton X-100-insoluble Fraction*

\begin{tabular}{lll}
\hline & $\begin{array}{l}\text { Actin } \\
\text { depolymerized } \\
\text { (\% of total } \\
\text { Inclusion in lysis } \\
\text { buffer }\end{array}$ & $\begin{array}{l}\text { GP Ib released } \\
\text { (\% of total in Triton } X-100- \\
\text { insoluble fraction) }\end{array}$ \\
\hline DNase I & $39.6 \pm 3.6 \ddagger$ & $20.3 \pm 1.9 \ddagger$ \\
$\mathrm{Ca}^{2+}$ & $34.5 \pm 2.6 \ddagger$ & $8.1 \pm 9.7$ \\
$\mathrm{Ca}^{2+}$, DNase I & $54.9 \pm 6.0 \ddagger$ & $36.3 \pm 4.7 \ddagger$ \\
\hline
\end{tabular}

* ${ }^{3} \mathrm{H}$-labeled platelets were lysed by addition of an equal volume of $2 \%$ Triton X-100, $10 \mathrm{mM}$ EGTA, $2 \mathrm{mg} / \mathrm{ml}$ leupeptin, $100 \mathrm{mM}$ benzamidine, $2 \mathrm{mM}$ phenylmethylsulfonyl fluoride, and $100 \mathrm{mM}$ Tris- $\mathrm{HCl}$, $\mathrm{pH} 7.4$, which also contained $2 \mathrm{mg} / \mathrm{ml}$ DNase I as indicated. Where indicated, the presence of $\mathrm{Ca}^{2+}$ was achieved by omitting EGTA from the lysis buffer. Triton X-100-insoluble actin filaments were isolated by centrifugation at $100,000 \mathrm{~g}$ for $3 \mathrm{~h}$, and the actin filament and GP Ib contents were determined. Values given are mean \pm standard error from three donors.

$¥$ Significant differences relative to controls that had no addition; $P<0.005$ in a two-sided, paired $t$ test. 

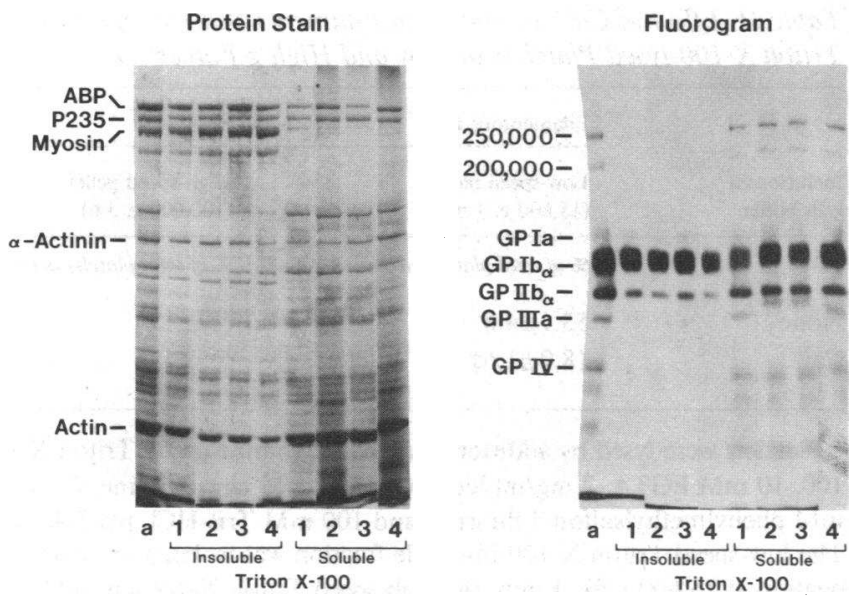

Figure 4. Effect of actin depolymerization on recovery of ${ }^{3} \mathrm{H}$-labeled glycoproteins in the Triton X-100-insoluble fraction. ${ }^{3} \mathrm{H}$-labeled platelets suspended in a Tyrode's solution that contained $1.8 \mathrm{mM} \mathrm{Ca}^{2+}$ were solubilized directly (lane $a$ ) or lysed by addition of $(a)$ an equal volume of buffer containing $2 \%$ Triton X-100, 10 mM EGTA, $2 \mathrm{mg} /$ $\mathrm{ml}$ leupeptin, $100 \mathrm{mM}$ benzamidine, $2 \mathrm{mM}$ phenylmethanesulfonyl fluoride, and $100 \mathrm{mM}$ Tris- $\mathrm{HCl}, \mathrm{pH} 7.4$ (lane 1 ), (b) the same buffer also containing $2 \mathrm{mg} / \mathrm{ml}$ DNase I (lane 2), (c) the same buffer lacking EGTA (lane 3), or (d) the same buffer lacking EGTA but also containing $2 \mathrm{mg} / \mathrm{ml} \mathrm{DNase} \mathrm{I} \mathrm{(lane} \mathrm{4).} \mathrm{Lysates} \mathrm{were} \mathrm{incubated} \mathrm{at} 4^{\circ} \mathrm{C}$ for 30 min, centrifuged for $3 \mathrm{~h}$ at $100,000 \mathrm{~g}$, and the Triton X-100-insoluble and -soluble fractions analyzed on SDS-polyacrylamide gels containing $7.5 \%$ acrylamide for the detection of protein with Coomassie brilliant blue or $5 \%$ acrylamide for detection of ${ }^{3} \mathrm{H}$-labeled glycoproteins by fluorography. ABP, actin-binding protein; P235, platelet polypeptide of $M_{\mathrm{r}}=235,000$.

showed that depolymerization of actin filaments by DNase I was accompanied by the release of actin-binding protein into the Triton X-100-soluble fraction. The recovery of the other polypeptides in the Triton X-100-insoluble fraction appeared to be independent of the presence of actin. There was no evidence of any proteolysis caused by the presence of DNase I (Fig. 4). Examination of the fluorogram obtained from ${ }^{3} \mathrm{H}$-labeled platelets (Fig. 4), showed that depolymerization of actin by DNase I was accompanied by a decreased recovery of GP Ib in the Triton X100 -insoluble fraction and an increased recovery of the glycoprotein in the Triton X-100-soluble fraction. Quantitation of the amount of GP Ib in the Triton X-100-insoluble fraction showed that the release of GP Ib was greatest when DNase I was added in the presence of $\mathrm{Ca}^{2+}$, which caused increased depolymerization of actin filaments (Table I). Longer exposures of the gel shown in Fig. 4 revealed that the recovery of most of the other ${ }^{3} \mathrm{H}$-labeled glycoproteins in the Triton X-100-insoluble fraction was also decreased when actin filaments were depolymerized by DNase I (data not shown). The only exception was GP IV, the Triton X-100 insolubility of which was independent of the actin filament content.

In contrast to DNase $\mathrm{I}, \mathrm{Ca}^{2+}$ had little effect on the recovery of ${ }^{3} \mathrm{H}$-labeled glycoproteins in the Triton X-100-insoluble fraction, despite the fact that it caused depolymerization of comparable amounts of actin filaments (Table I and Fig. 4).

Isolation of the membrane skeleton by differential centrifugation. The finding that depolymerization of actin filaments by DNase I, but not by $\mathrm{Ca}^{2+}$, resulted in the release of GP Ib from the Triton X-100-insoluble fraction suggested that GP Ib might be bound to a pool of actin filaments that could be depolymerized by DNase I but was resistant to depolymerization by gelsolin. In a previous report from this laboratory (4), we have shown that actin filaments in unstimulated, discoid platelets require high $g$ forces $(100,000 g$ for $3 \mathrm{~h})$ to be sedimented from Triton $\mathrm{X}-100$ lysates. In contrast, in platelets that have lost their discoid shape as a result of centrifugation in the absence of inhibitors of platelet function (such as prostacyclin), the majority of the filaments become cross-linked into networks that can be sedimented at low $g$ forces $(15,600 \mathrm{~g}$ for $4 \mathrm{~min})(4,28)$. However, we have observed that a small percentage of actin filaments always remains in a form that requires high $g$ forces to be sedimented. In the present study, experiments were designed to determine with which filaments the membrane glycoproteins were associated.

Cross-linking of actin filaments was induced either by washing platelets at ambient temperatures in the absence of prostacyclin or by labeling them by the sodium metaperiodate/sodium $\left[{ }^{3} \mathrm{H}\right.$ ]borohydride method, a procedure that was found to cause partial activation of platelets. Cross-linked filaments were isolated by centrifugation of Triton X-100 lysates at low $g$ forces, and the remaining filaments were subsequently isolated from the Triton X-100 supernatant by high-speed centrifugation. In accord with previous publications $(10,28)$, the only major Coomassie brilliant blue-stained polypeptide recovered with the actin filaments sedimenting at low $g$ forces was actin-binding protein (Fig. 5). As reported by others (36), some $\alpha$-actinin was also

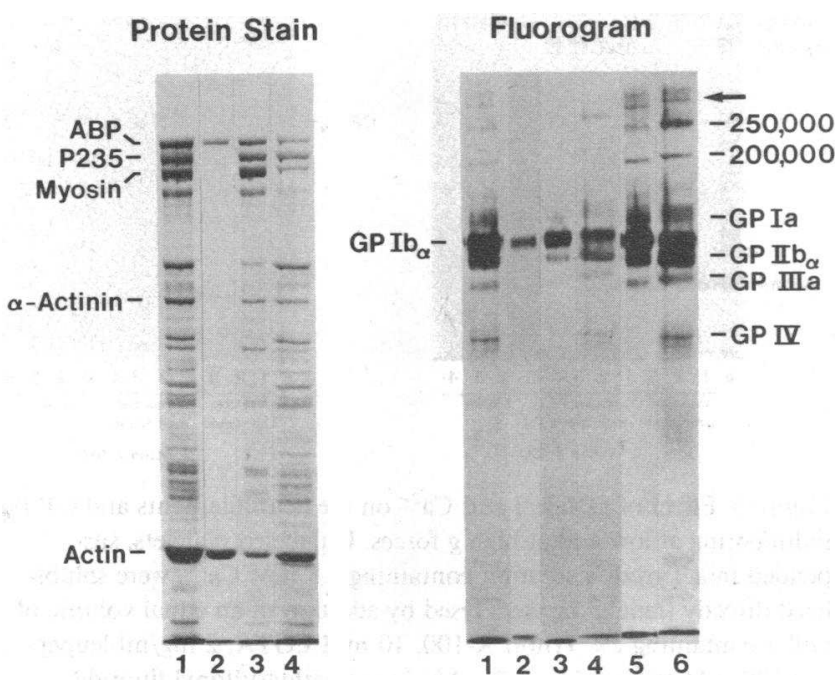

Figure 5. Recovery of ${ }^{3} \mathrm{H}$-labeled glycoproteins with Triton X-100-insoluble actin filaments sedimented at low and high $g$ forces. Platelets, surface-labeled by the sodium metaperiodate/sodium $\left[{ }^{3} \mathrm{H}\right]$ borohydride method, were suspended at $1 \times 10^{9}$ platelets $/ \mathrm{ml}$ in Tyrode's solution and solubilized directly into an SDS-containing buffer (lane 1 ), or lysed by addition of an equal volume of a buffer containing $2 \%$ Triton $\mathrm{X}-100,10 \mathrm{mM}$ EGTA, $2 \mathrm{mg} / \mathrm{ml}$ leupeptin, and $100 \mathrm{mM}$ Tris- $\mathrm{HCl}$, $\mathrm{pH}$ 7.4. Lysates were centrifuged for $4 \mathrm{~min}$ at $15,600 \mathrm{~g}$ and the Triton $\mathrm{X}-100$ supernatant centrifuged for a further $3 \mathrm{~h}$ at $100,000 \mathrm{~g}$. The lowspeed sediment (lane 2), the high-speed sediment (lanes 3 and 5), and the high-speed supernatant (lanes 4 and 6) were analyzed on SDSpolyacrylamide gels containing $7.5 \%$ acrylamide for detection of protein with Coomassie brilliant blue or $5 \%$ acrylamide for detection of ${ }^{3} \mathrm{H}$-labeled glycoproteins by fluorography. The fractions electrophoresed in lanes 5 and 6 are the same as those in lanes 3 and 4, except that they were subsequently exposed for a longer period of time. ABP, actin-binding protein; P235, platelet polypeptide of $M_{\mathrm{r}}=235,000$. 
recovered with these filaments. The remaining Triton X-100insoluble polypeptides required high-speed centrifugation for their sedimentation, as did a small amount of the filamentous actin (Fig. 5, lane 3). Comparison of the two Triton X-100insoluble fractions showed that most of the Triton X-100-insoluble glycoproteins were recovered with the small amount of filamentous actin that required high $\mathbf{g}$ forces for its sedimentation (Fig. 5).

Fig. 6 shows that those filaments that could be sedimented at low $g$ forces were depolymerized by addition of either DNase I or $\mathrm{Ca}^{2+}$ to the Triton X-100 lysis buffer. In contrast, those filaments requiring high $g$ forces for their sedimentation were depolymerized only by DNase I, with the effect of DNase I being greatest in the presence of $\mathrm{Ca}^{2+}$ (Fig. 6). The $\mathrm{Ca}^{2+}$ alone did not depolymerize these actin filaments (Fig. 6 and Table II). This experiment was performed with unlabeled platelets, therefore the effect of DNase I and $\mathrm{Ca}^{2+}$ on the distribution of GP Ib was determined on immunoblots using antibody against glycocalicin. Fig. 6 shows that the release of GP Ib from the high-speed Triton $\mathrm{X}$-100-insoluble fraction correlated with the extent of depolymerization of the actin filaments.

Fig. 7 shows the results of an experiment in which platelets that had not been surface labeled were stimulated with thrombin for increasing lengths of time. The experiment was performed
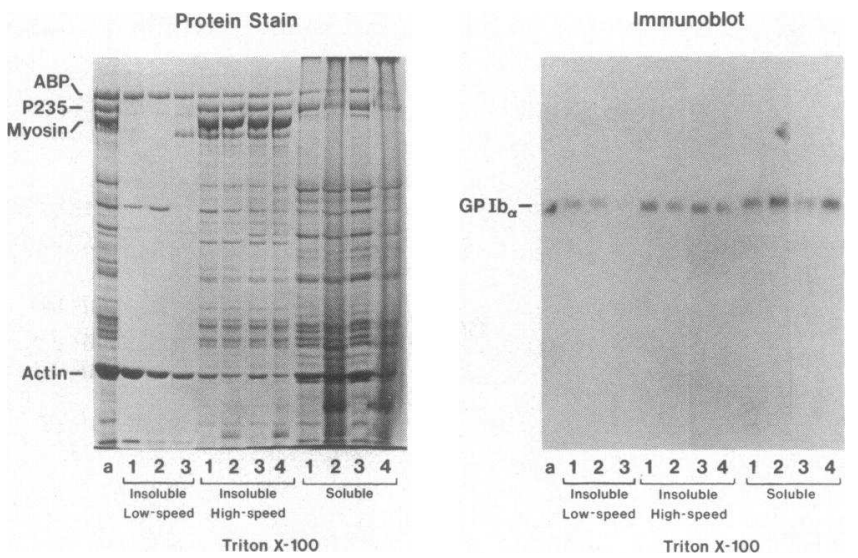

Figure 6. Effect of DNase $\mathrm{I}$ and $\mathrm{Ca}^{2+}$ on the actin filaments and GP Ib sedimenting at low and at high $g$ forces. Unlabeled platelets, suspended in a Tyrode's solution containing $1.8 \mathrm{mM} \mathrm{Ca}^{2+}$, were solubilized directly (lane $a$ ) or were lysed by addition of an equal volume of buffer containing $2 \%$ Triton X-100, $10 \mathrm{mM}$ EGTA, $2 \mathrm{mg} / \mathrm{ml}$ leupeptin, $100 \mathrm{mM}$ benzamidine, $2 \mathrm{mM}$ phenylmethylsulfonyl fluoride, and $100 \mathrm{mM}$ Tris-HCl, pH 7.4 (lane 1 ). The low-speed Triton X-100insoluble fraction was isolated by centrifugation at $15,600 \mathrm{~g}$ for $4 \mathrm{~min}$; the high-speed Triton X-100-insoluble and -soluble fractions were isolated by the subsequent centrifugation of the low-speed supernatant at $100,000 \mathrm{~g}$ for $3 \mathrm{~h}$. The effect of DNase I or $\mathrm{Ca}^{2+}$ on the actin filaments in the low-speed sediment was examined by adding $0.1 \mathrm{vol}$ of $10 \mathrm{mg} /$ $\mathrm{ml} \mathrm{DNase}$ I that was dissolved in the lysis buffer (lane 2) or $3.5 \mu \mathrm{l}$ of 1 $\mathrm{M}$ calcium chloride and $3.5 \mu \mathrm{l}$ of $1 \mathrm{M}$ sodium hydroxide to each $\mathrm{ml}$ of lysate (lane 3). The effect of DNase I (lane 2), $\mathrm{Ca}^{2+}$ (lane 3), or DNase I plus $\mathrm{Ca}^{2+}$ (lane 4 ) on the actin filaments requiring high-speed centrifugation for their sedimentation was examined by addition of the agents to the supernatant remaining after low-speed centrifugation. The Triton X-100-insoluble and -soluble fractions were analyzed on SDS-polyacrylamide gels containing $7.5 \%$ acrylamide. Polypeptides were detected with Coomassie brilliant blue, and GP Ib was detected on immunoblots. ABP, actin-binding protein; P235, platelet polypeptide of $M_{\mathrm{r}}=235,000$.
Table II. Effect of $\mathrm{Ca}^{2+}$ on the Actin Filaments Sedimenting from Triton X-100-lysed Platelets at Low and High $g$ Forces*

\begin{tabular}{lll}
\hline & Filamentous actin & \\
\cline { 2 - 3 } $\begin{array}{l}\text { Inclusion in } \\
\text { lysis buffer }\end{array}$ & $\begin{array}{l}\text { Low-speed pellet } \\
(15,600 \mathrm{~g}, 4 \mathrm{~min})\end{array}$ & $\begin{array}{l}\text { High-speed pellet } \\
(100,000 \mathrm{~g}, 3 \mathrm{~h})\end{array}$ \\
\hline & $\%$ of total platelet actin & \% of total platelet actin \\
& $53.1 \pm 4.8$ & $5.7 \pm 1.1$ \\
None & $18.9 \pm 1.6 \ddagger$ & $5.5 \pm 1.4$ \\
$\mathrm{Ca}^{2+}$ & & \\
\hline
\end{tabular}

* Platelets were lysed by addition of an equal volume of $2 \%$ Triton X$100,10 \mathrm{mM}$ EGTA, $2 \mathrm{mg} / \mathrm{ml}$ leupeptin, $100 \mathrm{mM}$ benzamidine, 2 $\mathrm{mM}$ phenylmethylsulfonyl fluoride, and $100 \mathrm{mM}$ Tris- $\mathrm{HCl}, \mathrm{pH} 7.4$. The low-speed Triton X-100-insoluble fraction was isolated by centrifugation at $15,600 \mathrm{~g}$ for $4 \mathrm{~min}$; the high-speed Triton X-100-insoluble fraction was isolated by the subsequent centrifugation of the low-speed supernatant at $100,000 \mathrm{~g}$ for $3 \mathrm{~h}$. The effect of $\mathrm{Ca}^{2+}$ on the actin in the low-speed sediment was determined by adding $3.5 \mu \mathrm{l}$ of $1 \mathrm{M}$ calcium chloride and $3.5 \mu \mathrm{l}$ of $1 \mathrm{M}$ sodium hydroxide to each $\mathrm{ml}$ of platelet lysate, whereas the effect on the actin in the high-speed sediment was determined by adding the calcium chloride and sodium hydroxide to the supernatant obtained after the low-speed centrifugation. Values given are mean \pm standard error from three donors.

$¥$ Significant depolymerization relative to the samples that had no addition; $P<0.005$ in a two-sided, paired $t$ test.

in the presence of EDTA to prevent platelet aggregation and thus to permit the efficient lysis of activated platelets with Triton X-100 and the subsequent separation of the Triton X-100-insoluble actin filaments into those that sediment at low $g$ forces and those that require high $g$ forces for their sedimentation. Consistent with previous reports $(28,37)$, activation of platelets resulted in rapid polymerization of actin, as indicated by decreased actin in the Triton X-100-soluble fraction (Fig. 7). The increased actin filament content was observed entirely in the low-speed Triton X-100-insoluble fraction. After an initial decrease, the amount of actin in the high-speed Triton X-100insoluble fraction remained constant. The previously reported increases in the amount of actin-binding protein, myosin, $\alpha$ actinin, and fibrin sedimenting at low $g$ forces with the actin filaments from thrombin-activated platelets $(10,14,28,38)$ were accompanied by decreases in the amount of these proteins sedimenting at high $g$ forces. Examination of the distribution of GP Ib on immunoblots confirmed that most of the GP Ib was recovered with those filaments requiring high-speed centrifugation for their sedimentation and showed that the distribution of this glycoprotein between the Triton X-100-insoluble and -soluble fractions was not changed during platelet activation.

Isolation of the membrane skeleton by sucrose density centrifugation. Fig. 8 shows the results of an experiment in which GP Ib associated with the membrane skeleton was separated from the Triton X-100-soluble form of GP Ib by sedimentation through sucrose density gradients. The distribution of GP Ib in the sucrose gradient fractions was determined by fluorography of SDS-polyacrylamide gels of each fraction. Glycoprotein Ib was detected in three positions in the gradient. The greatest concentration of GP Ib was observed in fractions containing proteins with sedimentation coefficients centering at 8.4 S. The GP IIbIIIa complex, shown previously to have a sedimentation coefficient of 8.6 S (23), was also present in these fractions. Lesser amounts of GP Ib were also recovered in several fractions lower 


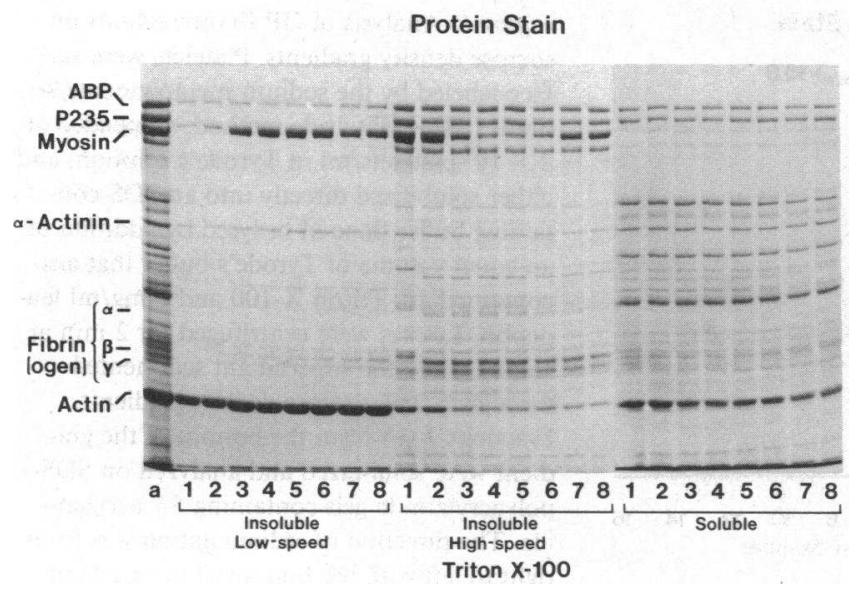

Immunoblot

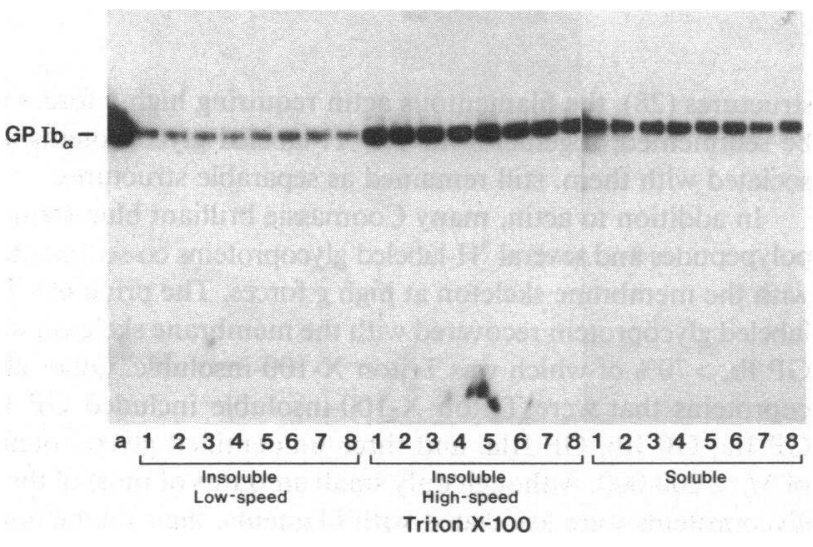

Figure 7. Effect of platelet activation on the recovery of GP Ib with actin filaments requiring low-speed and high-speed centrifugation for their sedimentation. Unlabeled platelets, were solubilized directly (lane a) or were incubated with $0.1 \mathrm{NIH} \mathrm{U}$ of thrombin/ml for 0 time (lane 1); 5 s (lane 2); 15 s (lane 3); 30 s (lane 4); 60 s (lane 5); 2 min (lane 6); 5 min (lane 7); 15 min (lane 8). Incubations were terminated by addition of an equal volume of buffer containing $2 \%$ Triton X-100, 10 $\mathrm{mM}$ EGTA, and $100 \mathrm{mM}$ Tris- $\mathrm{HCl}, \mathrm{pH}$ 7.4. Lysates were centrifuged for 4 min at $15,600 \mathrm{~g}$ and the Triton X-100 supernatant centrifuged for a further $3 \mathrm{~h}$ at $100,000 \mathrm{~g}$. The Triton X-100-insoluble and -soluble fractions were analyzed on SDS-polyacrylamide gels containing $7.5 \%$ acrylamide. Proteins were detected with Coomassie brilliant blue and GP Ib was detected on immunoblots. For the immunoblots, the amount of each fraction electrophoresed originated from comparable amounts of platelets, but for Coomassie brilliant blue staining, the whole platelet sample and Triton X-100-insoluble fractions all originated from twice the number of platelets as the Triton X-100-soluble fractions. ABP, actin-binding protein; P235, platelet polypeptide of $M_{\mathrm{r}}$ $=235,000$.

in the sucrose gradient, corresponding to sedimentation coefficients ranging from 10.3 to $15.0 \mathrm{~S}$ (Fig. 8). Finally, variable amounts of GP Ib were also recovered in the pellet that sedimented to the bottom of the gradient (data not shown). In contrast, purified GP Ib was recovered with a sedimentation coefficient of 5.0 S (data not shown). Thus, the GP Ib in platelet lysates existed in multiple forms, all of which sedimented faster than the purified protein. These data suggest that GP Ib was associated with additional proteins in the Triton X-100 lysates of platelets. Sedimentation of Triton X-100-soluble fractions through sucrose density gradients showed that the GP Ib with a sedimentation coefficient of $8.4 \mathrm{~S}$ was the Triton X-100-soluble form of the glycoprotein (data not shown). The GP Ib sedimenting lower in the gradient therefore represented that which was associated with the membrane skeleton.

Fig. 8 also shows the Coomassie brilliant blue-stained gels of the same sucrose fractions analyzed in the fluorogram depicted in Fig. 8. Although many polypeptides were present in fractions sedimenting at $8.4 \mathrm{~S}$, the polypeptide content of the fractions sedimenting between 10.3 and $15.0 \mathrm{~S}$ was much more limited. The major Coomassie brilliant blue staining polypeptide in these fractions was one of $M_{\mathrm{r}}=250,000$. This was identified as actinbinding protein on the basis of its reactivity on Western blots with a previously characterized (27), affinity-purified antibody against actin-binding protein (data not shown). Purified actinbinding protein, isolated from fresh human platelets, sedimented with a sedimentation coefficient of $10.0 \mathrm{~S}$ in the sucrose gradients used in the present study (data not shown), thus the recovery of actin-binding protein with sedimentation coefficients ranging to 15.0 S suggested that actin-binding protein was associated with other proteins in these fractions. As shown in the fluorogram in Fig. 9, longer exposure of gels revealed that in addition to GP Ib, GP Ia and small amounts of the minor glycoprotein of $M_{\mathrm{r}}$ $=250,000$ also co-sedimented with actin-binding protein in the fractions with sedimentation coefficients of 10.3-15.0 S. Although not visible on the gels containing 5\% acrylamide (a condition that is necessary for the efficient resolution of GP Ib in Fig. 8), actin was demonstrated to be present in these fractions by electrophoresis of sucrose gradient fractions on gels containing 7.5\% acrylamide (Fig. 9).

Isolation of the membrane skeleton from membrane vesicles. The co-sedimentation of actin-binding protein, GP Ib, GP Ia, and the glycoprotein of $M_{\mathrm{r}}=250,000$ with the high-speed actin filaments from Triton X-100 lysates of unstimulated platelets and the co-isolation of these proteins on sucrose gradients suggested that these were the components of the membrane skeleton in platelets. As a test of this hypothesis, plasma membranes were isolated from platelets and examined for the presence of each of the proteins. The major proteins, detected by Coomassie brilliant blue, were actin, actin-binding protein, GP IIb, and GP IIIa (Fig. 10). The identity of each of these proteins was confirmed on immunoblots (data not shown). As shown in the immunoblot in Fig. 10, GP Ib was also present in the membrane fraction. After extraction of the membranes with Triton X-100, most of the GP IIb and GP IIIa was solubilized. In contrast, much of the GP Ib was insoluble in Triton X-100 and was recovered with the membrane skeleton. The major components of this skeleton were actin, actin-binding protein, and GP Ib (Fig. 10, lane 2). In experiments using ${ }^{3} \mathrm{H}$-labeled platelets, it was found that $\mathrm{GP}$ Ia and the membrane glycoprotein of $M_{\mathrm{r}}=250,000$ were also recovered with the membrane skeleton obtained from isolated membrane vesicles (data not shown).

\section{Discussion}

Previous studies indicate a close association of actin filaments with platelet plasma membrane: submembranous networks of actin filaments have been demonstrated morphologically in platelets, ${ }^{1}$ and actin co-isolates with membranes during their purification $(7,8)$. It has therefore been assumed that actin filaments within platelets are attached to the plasma membrane. Although one study using platelets surface-labeled by lactoper- 

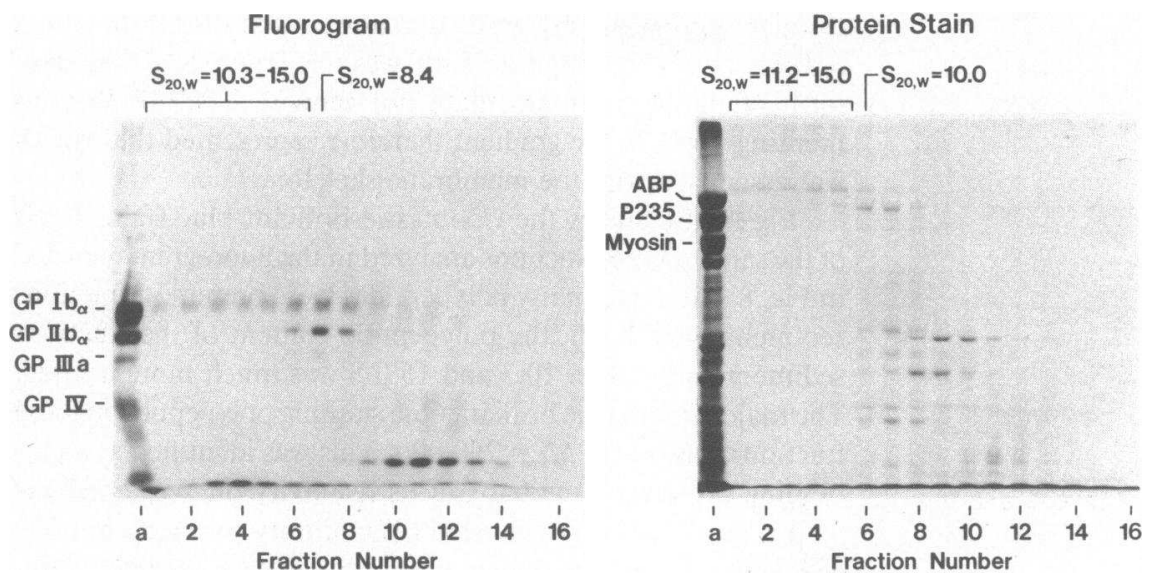

Figure 8. Analysis of GP Ib interactions on sucrose density gradients. Platelets were surface-labeled by the sodium metaperiodate/sodium $\left[{ }^{3} \mathrm{H}\right]$ borohydride method, suspended at $2 \times 10^{9}$ platelets $/ \mathrm{ml}$ in Tyrode's solution, and either solubilized directly into an SDS-containing buffer (lane $a$ ) or lysed by addition of an equal volume of Tyrode's buffer that also contained $2 \%$ Triton X-100 and $2 \mathrm{mg} / \mathrm{ml} \mathrm{leu}$ peptin. Lysates were centrifuged for $2 \mathrm{~min}$ at $15,600 \mathrm{~g}$ and the supernatant sedimented through 5-25\% sucrose density gradients. Fractions 1-16 from the bottom of the gradient were solubilized and analyzed on SDSpolyacrylamide gels containing $5 \%$ acrylamide. The direction of sedimentation was from right to left with the bottom of the gradient

on the left. ${ }^{3} \mathrm{H}$-labeled glycoproteins were detected by fluorography, and proteins were detected by staining with Coomassie brilliant blue. Sedimentation coefficients were determined as described in Methods. ABP, actin-binding protein; P235, platelet polypeptide of $M_{\mathrm{r}}=235,000$.

oxidase-catalyzed iodination implicated GP IIb and GP IIIa as attachment sites in platelets that had aggregated, no major iodinated glycoprotein was recovered with filaments isolated by low-speed centrifugation from Triton X-100 lysates of unstimulated platelets (10). However, we have demonstrated that some of the filamentous actin in platelets does not sediment at the low $g$ forces used in the previous study but requires high $g$ forces to be sedimented (28). In the present study, it is shown that these latter filaments represent a specific membrane skeleton that is distinct from the rest of the cytoskeleton.

Three lines of evidence support the conclusion that platelets contain a distinct membrane skeleton. First, by labeling platelets with the sodium metaperiodate/sodium $\left[{ }^{3} \mathrm{H}\right]$ borohydride procedure, it was shown that several glycoproteins were selectively associated with the filaments requiring high $g$ forces for their sedimentation. Second, unlike those filaments that sedimented at low $g$ forces, those requiring high $g$ forces for their sedimentation were resistant to depolymerization by gelsolin. Third, during platelet activation, when actin filaments that could be sedimented at low $g$ forces underwent increased polymerization and, as reported previously, became cross-linked into dense structures (28), the filamentous actin requiring high $g$ forces to be sedimented, together with the ${ }^{3} \mathrm{H}$-labeled glycoproteins associated with them, still remained as separable structures.

In addition to actin, many Coomassie brilliant blue-stained polypeptides and several ${ }^{3} \mathrm{H}$-labeled glycoproteins co-sedimented with the membrane skeleton at high $g$ forces. The principal ${ }^{3} \mathrm{H}$ labeled glycoprotein recovered with the membrane skeleton was GP Ib, $>70 \%$ of which was Triton X-100-insoluble. Other glycoproteins that were Triton X-100-insoluble included GP Ia, GP IIa, GP IIb, GP IIIa, and three unidentified glycoproteins of $M_{\mathrm{r}}>200,000$. Although only small amounts of most of these glycoproteins were associated with filaments, their interactions were specific as indicated by the absence of other, more intensely ${ }^{3} \mathrm{H}$-labeled glycoproteins from the Triton X-100-insoluble fraction.

The sodium metaperiodate/sodium $\left[{ }^{3} \mathrm{H}\right]$ borohydride procedure used to label the surface glycoproteins includes a step in which platelets are incubated at $4^{\circ} \mathrm{C}$, a temperature that has been shown to cause at least partial activation of platelets (4). Prostacyclin was therefore included in all buffers to minimize this effect; however, the appearance of small aggregates of plate-
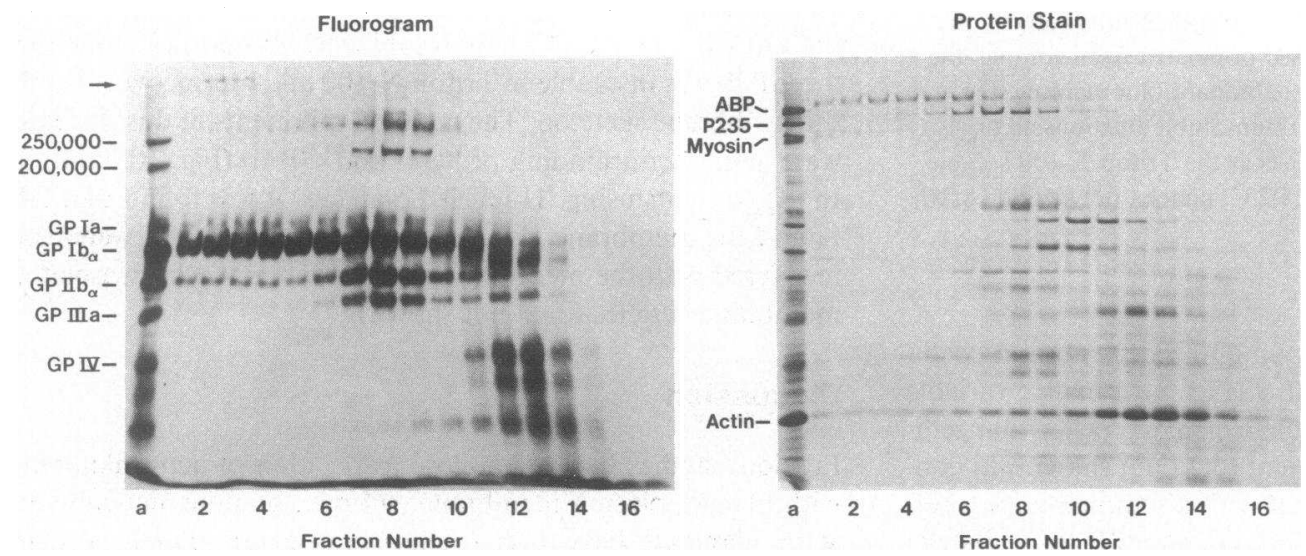

Figure 9. Isolation of the membrane skeleton on sucrose density gradients. Platelets were surface labeled by the sodium metaperiodate/sodium $\left[{ }^{3} \mathrm{H}\right]$ borohydride method, suspended at $2 \times 10^{9}$ platelets $/ \mathrm{ml}$ in Tyrode's solution, and either solubilized directly into an SDS-containing buffer (lane $a$ ) or lysed by addition of an equal volume of Tyrode's buffer that also contained $2 \%$ Triton $\mathrm{X}$ 100 and $2 \mathrm{mg} / \mathrm{ml}$ leupeptin and sedimented through sucrose gradients as described in

the legend to Fig. 8. Fractions 1-17 from the bottom of the gradient were solubilized and analyzed on SDS-polyacrylamide gels containing 5\% acrylamide for detection of ${ }^{3} \mathrm{H}$-labeled glycoproteins or $7.5 \%$ acrylamide for detection of Coomassie brilliant blue-stained polypeptides. The direction of sedimentation was from right to left with the bottom of the gradient on the left. ${ }^{3} \mathrm{H}$-labeled glycoproteins were detected by fluorography and proteins by staining with Coomassie brilliant blue. ABP, actin-binding protein; P235, platelet polypeptide of $M_{\mathrm{r}}=235,000$. 
Protein Stain

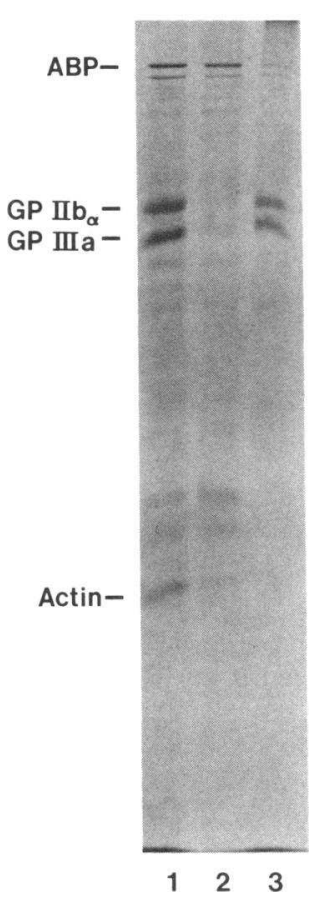

Immunoblot

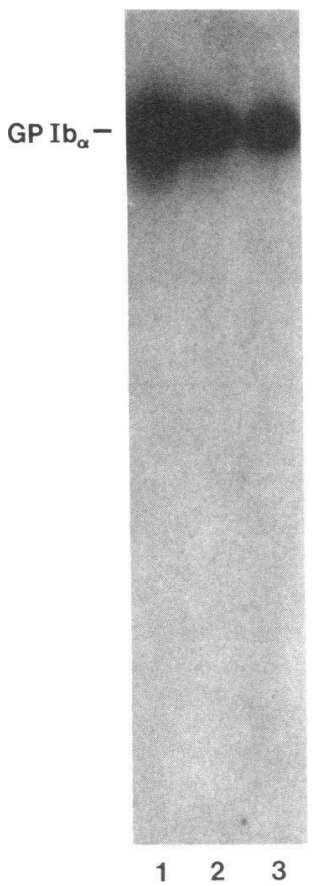

Figure 10. Isolation of platelet membranes and the Triton X-100-insoluble membrane skeleton. Platelets were sonicated, and membrane vesicles isolated as described in Methods. Isolated membranes (lane 1) were extracted with Triton X-100 and the Triton X-100-insoluble (lane 2) and -soluble fractions (lane 3) obtained by centrifugation for 3 $\mathrm{h}$ at $100,000 \mathrm{~g}$. Samples were solubilized and analyzed on SDS-polyacrylamide gels containing $7.5 \%$ acrylamide. Proteins were detected with Coomassie brilliant blue, and GP Ib was detected on immunoblots. The Triton X-100-soluble fraction shown in lane 3 originated from half as many membranes as did the Triton X-100-insoluble fraction shown in lane 2. ABP, actin-binding protein.

lets indicated that some activation still occurred. Final suspensions of labeled platelets were therefore incubated with prostacyclin at $37^{\circ} \mathrm{C}$ in an attempt to restore them to their unactivated state (4) before experiments were initiated. To circumvent the potential problem of activation during radiolabeling, the recovery of membrane glycoproteins with actin filaments was also studied in unlabeled platelets. These platelets were washed by a method previously shown to allow the isolation of completely unactivated discoid platelets (4). Glycoproteins in fractions isolated from these platelets were detected on immunoblots, which confirmed that much of GP Ib was recovered with the actin filaments. In contrast, GP IIb and GP IIIa were not detected on the immunoblots of Triton X-100-insoluble fractions from unlabeled, discoid platelets, suggesting that the recovery of small amounts of these glycoproteins with filaments from ${ }^{3} \mathrm{H}$-labeled platelets resulted from some activation of the platelets during the surfacelabeling procedure.

Three approaches were used to determine which of the polypeptides in the high-speed Triton X-100-insoluble fraction from unstimulated platelets sedimented in this fraction because they were associated with the membrane skeleton. First, filaments were depolymerized with DNase I under conditions in which no proteolytic activity could be detected. The results of this approach indicated that, with the exception of GP IV, the Triton $\mathrm{X}-100$ insolubility of all of the ${ }^{3} \mathrm{H}$-labeled glycoproteins resulted from their association with actin filaments. Actin-binding protein was the only major Coomassie brilliant blue-stained protein that was Triton X-100-insoluble as a result of its association with actin filaments. The second approach used to study the composition of the membrane skeleton was the analysis of platelet lysates on sucrose density gradients. This approach showed that GP Ia, GP Ib, and a ${ }^{3} \mathrm{H}$-labeled glycoprotein of $M_{\mathrm{r}}=250,000$ co-migrated with actin filaments and actin-binding protein, indicating that these are the major components of the membrane skeleton from unstimulated platelets. The composition of the membrane skeleton was confirmed by demonstrating that each of the components was present in isolated membrane vesicles and that the membrane skeleton obtained as the Triton X-100insoluble residue from isolated membrane vesicles contained actin, actin-binding protein, GP Ia, GP Ib, and the ${ }^{3} \mathrm{H}$-labeled glycoprotein of $M_{\mathrm{r}}=250,000$.

While the present manuscript was under review, Okita et al. (39) reported the co-isolation of small amounts of actin-binding protein with GP Ib on affinity columns of API, a monoclonal antibody against GP Ib. Experiments from our laboratory have shown that actin-binding protein serves as a linkage protein that mediates the attachment of actin filaments to GP Ib, GP Ia, and the membrane glycoprotein of $M_{\mathrm{r}}=250,000$ (40).

Glycoprotein Ib is one of the major plasma membrane glycoproteins in platelets, being present in $\sim 25,000$ copies per platelet (41). The association of $>70 \%$ of this glycoprotein with the actin filaments of the membrane skeleton therefore suggests that this glycoprotein is a primary attachment site for the membrane skeleton in unstimulated platelets. In a recent morphologic study, we have shown that the majority of actin filaments in unstimulated, discoid platelets appear to be concentrated beneath the plasma membrane. ${ }^{1}$ Thus, in discoid cells, the filaments of the cytoskeleton, as well as those of the membrane skeleton, may be attached to membrane glycoproteins. Alternatively, the peripheral location of the cytoskeleton could result from its interaction with other peripheral structures such as microtubules or the membrane skeleton. In the previous study, filaments in platelets that had lost their discoid shape during their isolation by centrifugation procedures appeared to be more centralized than those in discoid platelets, ${ }^{1}$ suggesting that disruption of the interaction that concentrates the cytoskeleton at the periphery may be one of the very early steps in platelet activation. In contrast, the present study shows that the interaction of the membrane skeleton with the plasma membrane remains intact during platelet activation. Because the platelets used in the present study were necessarily surface-labeled by a procedure known to cause some activation of platelets, an interaction between filaments of the cytoskeleton and plasma membrane glycoproteins may have gone undetected in this study.

Solum and Olsen (42) recently reported that GP Ib was present in the Triton X-100-insoluble fraction of platelets. However, because these authors isolated the Triton X-100-insoluble fraction by low-speed centrifugation, they were presumably detecting only a small amount of the filament-associated GP Ib. In an earlier publication, Solum et al. (43) showed by crossed immunoelectrophoresis that GP Ib in the low-speed Triton X-100 supernatant was present in three forms. These forms were identified as glycocalicin, free GP Ib, and a high molecular weight complex of GP Ib with other unidentified proteins. The present report suggests that this high molecular weight form of $\mathrm{GP} \mathrm{Ib}$ represents GP Ib associated with actin filaments of the membrane skeleton. 
The use of sucrose density gradients in the present study permitted the demonstration of additional interactions involving GP Ib in platelet lysates. GP Ib that was not associated with the membrane skeleton in platelet lysates had a sedimentation coefficient of 8.4 S. Such a value is similar to that of the GP IIb-IIIa complex $\left(M_{\mathrm{r}}=265,000\right.$ [23]) and is markedly different from the sedimentation coefficient $(5.0 \mathrm{~S})$ of purified GP Ib, which has a $M_{\mathrm{r}}=160,000$ (29). This indicates that GP Ib is associated with an additional polypeptide(s), an interaction that is maintained in the presence of $\mathrm{Ca}^{2+}$-dependent proteolytic activity (40). A candidate for such a polypeptide is the one of $M_{\mathrm{r}}$ $=210,000$ reported previously to co-purify with GP Ib (44). Another candidate is GP IX, which has been shown to co-purify with GP Ib on anti-GP Ib monoclonal antibody affinity columns (45). The method of purifying GP Ib described in the present study presumably separated GP Ib from the other polypeptides to which it was associated in platelets. The results of sucrose density gradient sedimentation reported here suggest that the form identified as free GP Ib on crossed immunoelectrophoresis (43) may have been complexed with an additional unidentified protein(s).

The recovery of several glycoproteins with the membrane skeleton suggests that the filaments of this skeleton may be attached to more than one site on the plasma membrane of unactivated platelets. Such a mechanism would not be unprecedented. In erythrocytes, which are the only cell type in which the molecular nature of the interaction of actin filaments with integral membrane proteins has been described in detail, filaments are attached to spectrin, which is itself linked to at least two integral membrane proteins: glycophorin and band 3 (9). The interaction between spectrin and glycophorin is mediated by band 4.1 , whereas that between spectrin and band 3 is mediated by ankyrin $(9,46)$. Because spectrin, band 4.1 , and ankyrin have all been detected immunologically in platelets $(47,48)$, similar attachment mechanisms may exist within these cells. In addition, $\alpha$-actinin and vinculin, two other proteins thought to be involved in the attachment of actin filaments to plasma membranes in nonmuscle cells, have also been detected in platelets $(36,49)$, providing further support for the idea that actin filaments may be attached to the platelet membrane in a number of ways. Alternatively, the recovery of some of the glycoproteins with actin filaments might result from the presence of complexes of these glycoproteins with glycoproteins comprising the true attachment sites. GP Ib, for example, has been purified as a complex with a polypeptide of $M_{\mathrm{r}}=210,000$ (44). The latter glycoprotein might represent one of the high molecular weight glycoproteins recovered with actin filaments in the present study.

The attachment of a submembranous network of actin filaments to the plasma membrane of unstimulated platelets could, by analogy to the erythrocytes, have an important functional role in controlling the shape and deformability of the platelets. The involvement of GP Ib in such a mechanism is supported by the observation that platelets from Bernard-Soulier patients, which lack GP Ib (50), are unusually large and readily deformable $(51,52)$. In some cell types, the attachment of filaments to membrane glycoproteins has also been shown to influence the properties of the glycoproteins themselves, restraining their mobility in the plane of the membrane and, under certain conditions, directing their mobility $(6,53)$. It is thus reasonable to suggest that the properties of GP Ib may also be influenced by its attachment to actin filaments. Because GP Ib appears to be the receptor for von Willebrand factor and thus to be involved in supporting the adhesion of platelets to the subendothelium (54), regulation of the properties of GP Ib by its attachment to actin filaments could be of clinical significance.

\section{Acknowledgments}

The author wishes to thank Dr. David R. Phillips for many helpful discussions, Clifford Reynolds and Anne Baughan for excellent technical assistance, James X. Warger and Norma Jean Gargasz for graphics, Barbara Allen and Sally Gullatt Seehafer for editorial assistance, and Michele Prator for manuscript preparation.

This work was supported in part by New Investigator Award HL30657 from the National Institutes of Health.

\section{References}

1. White, J. G. 1971. Platelet microtubules and microfilaments: effects of cytochalasin B on structure and function. In Platelet Aggregation. J. Caen, editor. Masson et Cie, Paris. 15-52.

2. White, J. G., S. M. Burris, D. Tukey, C. Smith, and C. C. Clawson. 1984. Micropipette aspiration of human platelets: influence of microtubules and actin filaments on deformability. Blood. 64:210-214.

3. Bettex-Galland, M., and E. F. Lüscher. 1961. Thrombasthenina contractile protein from thrombocytes. Its extraction from human blood platelets and some of its properties. Biochim. Biophys. Acta. 49:536547.

4. Fox, J. E. B., J. K. Boyles, C. C. Reynolds, and D. R. Phillips. 1984. Actin filament content and organization in unstimulated platelets. J. Cell Biol. 98:1985-1991.

5. Fox, J. E. B. 1985. Platelet contractile proteins. In Biology of Platelets. D. R. Phillips and M. A. Shuman, editors. Academic Press, Inc., New York. In press.

6. Sheetz, M. P. 1983. Membrane skeletal dynamics: role in modulation of red cell deformability, mobility of transmembrane proteins, and shape. Semin. Hematol. 20:175-188.

7. Menashi, S., H. Weintroub, and N. Crawford. 1981. Characterization of human platelet surface and intracellular membranes isolated by free flow electrophoresis. J. Biol. Chem. 256:4095-4101.

8. Davies, G. E. 1984. Association of actin with the platelet membrane. Biochim. Biophys. Acta. 772:149-160.

9. Cohen, C. M. 1983. The molecular organization of the red cell membrane skeleton. Semin. Hematol. 20:141-158.

10. Phillips, D. R., L. K. Jennings, and H. H. Edwards. 1980. Identification of membrane proteins mediating the interaction of human platelets. J. Cell Biol. 86:77-86.

11. Phillips, D. R., and P. P. Agin. 1977. Platelet membrane defects in Glanzmann's thrombasthenia. Evidence for decreased amounts of two major glycoproteins. J. Clin. Invest. 60:535-545.

12. Berndt, M. C., and D. R. Phillips. 1981. Purification and preliminary physiochemical characterization of human platelet membrane glycoprotein V. J. Biol. Chem. 256:59-65.

13. Laemmli, U. K. 1970. Cleavage of structural proteins during the assembly of the head of bacteriophage T4. Nature (Lond.). 227:680-685.

14. Fox, J. E. B., and D. R. Phillips. 1982. Role of phosphorylation in mediating the association of myosin with the cytoskeletal structures of human platelets. J. Biol. Chem. 257:4120-4126.

15. Phillips, D. R., and P. P. Agin. 1977. Platelet plasma membrane glycoproteins. Evidence for the presence of nonequivalent disulfide bonds using nonreduced-reduced two-dimensional gel electrophoresis. J. Biol. Chem. 252:2121-2126.

16. O'Farrell, P. H. 1975. High resolution two-dimensional electrophoresis of proteins. J. Biol. Chem. 250:4007-4021.

17. Fox, J. E. B., C. C. Reynolds, and D. R. Phillips. 1983. Calciumdependent proteolysis occurs during platelet aggregation. J. Biol. Chem. 258:9973-9981. 
18. Clarke, J. T. 1964. Simplified "disc" (polyacrylamide gel) electrophoresis. Ann. N.Y. Acad. Sci. 121:428-436.

19. Towbin, H., T. Staehelin, and J. Gordon. 1979. Electrophoretic transfer of proteins from polyacrylamide gels to nitrocellulose sheets: procedure and some applications. Proc. Natl. Acad. Sci. USA. 76:43504354.

20. Martin, R. G., and B. N. Ames. 1961. A method for determining the sedimentation behavior of enzymes: application to protein mixtures. J. Biol. Chem. 236:1372-1379.

21. Markwell, M. A. K. 1982. A new solid-state reagent to iodinate proteins. I. Conditions for the efficient labeling of antiserum. Anal. Biochem. 125:427-432.

22. Bolton, A. E., and W. M. Hunter. 1973. The labelling of proteins to high specific radioactivities by conjugation to a ${ }^{125}$ I-containing acylating agent. Biochem. J. 133:529-539.

23. Jennings, L. K., and D. R. Phillips. 1982. Purification of glycoproteins IIb and III from human platelet plasma membranes and characterization of a calcium-dependent glycoprotein IIb-III complex. J. Biol. Chem. 257:10458-10466.

24. Newman, P. J., M. A. Knipp, and R. A. Kahn. 1982. Extraction and identification of human platelet integral membrane proteins using Triton X-114. Thromb. Res. 27:221-224.

25. Morrissey, J. H. 1981. Silver stain for proteins in polyacrylamide gels: a modified procedure with enhanced uniform sensitivity. Anal. Biochem. 117:307-310.

26. Okumura, T., C. Lombart, and G. A. Jamieson. 1976. Platelet glycocalicin. II. Purification and characterization. J. Biol. Chem. 251: 5950-5955.

27. Fox, J. E. B., D. E. Goll, C. C. Reynolds, and D. R. Phillips. 1985. Identification of two proteins (actin-binding protein and P235) that are hydrolyzed by endogenous $\mathrm{Ca}^{2+}$-dependent protease during platelet aggregation. J. Biol. Chem. 260:1060-1066.

28. Jennings, L. K., J. E. B. Fox, H. H. Edwards, and D. R. Phillips. 1981. Changes in the cytoskeletal structure of human platelets following thrombin activation. J. Biol. Chem. 256:6927-6932.

29. Clemetson, K. J. 1985. Glycoproteins of the platelet plasma membrane. In Platelet Membrane Glycoproteins. J. George, A. Nurden, and D. R. Phillips, editors. Plenum Publishing Co. New York. 51-85.

30. Clemetson, K. J., J. L. McGregor, E. James, M. Dechavanne, and E. F. Lüscher. 1982. Characterization of the platelet membrane glycoprotein abnormalities in Bernard-Soulier syndrome and comparison with normal by surface-labeling techniques and high-resolution two-dimensional gel electrophoresis. J. Clin. Invest. 70:304-311.

31. Solum, N. O., I. Hagen, C. Filion-Myklebust, and T. Staback. 1980. Platelet glycocalicin. Its membrane association and solubilization in aqueous media. Biochim. Biophys. Acta. 597:235-246.

32. Blikstad, I., F. Markey, L. Carlsson, T. Persson, and U. Lindberg. 1978. Selective assay of monomeric and filamentous actin in cell extracts, using inhibition of deoxyribonuclease I. Cell. 15:935-943.

33. Markey, F., T. Persson, and U. Lindberg. 1981. Characterization of platelet extracts before and after stimulation with respect to the possible role of profilactin as microfilament precursor. Cell. 23:145-153.

34. Lind, S. E., H. L. Yin, and T. P. Stossel. 1982. Human platelets contain gelsolin. A regulator of actin filament length. J. Clin. Invest. 69: 1384-1387.

35. Price, P. A. 1975. The essential role of $\mathrm{Ca}^{2+}$ in the activity of bovine pancreatic deoxyribonuclease. J. Biol. Chem. 250:1981-1986.

36. Rosenberg, S., A. Stracher, and K. Burridge. 1981. Isolation and characterization of a calcium-sensitive $\alpha$-actinin-like protein from human platelet cytoskeletons. J. Biol. Chem. 256:12986-12991.

37. Carlsson, L., F. Markey, I. Blikstad, T. Persson, and U. Lindberg. 1979. Reorganization of actin in platelets stimulated by thrombin as measured by DNase I inhibition assay. Proc. Natl. Acad. Sci. USA. 76 6376-6380.

38. Casella, J. F., N. C. Masiello, S. Lin, W. Bell, and M. B. Zucker. 1983. Identification of fibrinogen derivatives in the Triton-insoluble residue of human blood platelets. Cell Motil. 3:21-30.

39. Okita, J. R., D. Pidard, P. J. Newman, R. R. Montgomery, and T. J. Kunicki. 1985. On the association of glycoprotein Ib and actinbinding protein in human platelets. J. Cell Biol. 100:317-321.

40. Fox, J. E. B. 1985. Identification of actin-binding protein as the protein linking the membrane skeleton to glycoproteins on platelet plasma membranes. J. Biol. Chem. In press.

41. Coller, B. S., E. I. Peerschke, L. E. Scudder, and C. A. Sullivan. 1983. Studies with a murine monoclonal antibody that abolishes ristocetin-induced binding of von Willebrand factor to platelets: additional evidence in support of GP Ib as a platelet receptor for von Willebrand factor. Blood. 61:99-110.

42. Solum, N. O., and T. M. Olsen. 1984. Glycoprotein Ib in the Triton-insoluble (cytoskeletal) fraction of blood platelets. Biochim. Biophys. Acta. 799:209-220.

43. Solum, N. O., T. M. Olsen, G. O. Gogstad, I. Hagen, and F. Brosstad. 1983. Demonstration of a new glycoprotein Ib-related component in platelet extracts prepared in the presence of leupeptin. Biochim. Biophys. Acta. 729:53-61.

44. Nachman, R. L., T. Kinoshita, and B. Ferris. 1979. Structural analysis of human platelet membrane glycoprotein I complex. Proc. Natl. Acad. Sci. USA. 76:2952-2954.

45. Berndt, M. C., C. Gregory, B. H. Chong, H. Zola, and P. A. Castaldi. 1983. Additional glycoprotein defects in Bernard-Soulier's syndrome: confirmation of genetic basis by parental analysis. Blood. 62 : 800-807.

46. Anderson, R. A., and R. E. Lovrien. 1984. Glycophorin is linked by band 4.1 protein to the human erythrocyte membrane skeleton. Nature (Lond.). 307:655-658.

47. Davies, G. E., and C. M. Cohen. 1985. Platelets contain proteins immunologically related to red cell spectrin and protein 4.1. Blood. 65: $52-59$.

48. Bennett, V. 1979. Immunoreactive forms of human erythrocyte ankyrin are present in diverse cells and tissues. Nature (Lond.). 281:597599.

49. Langer, B. G., P. A. Gonella, and V. T. Nachmias. 1984. $\alpha-$ Actinin and vinculin in normal and thrombasthenic platelets. Blood. 63: 606-614.

50. Nurden, A. T., and J. P. Caen. 1975. Specific roles for platelet surface glycoproteins in platelet function. Nature (Lond.). 255:720-722.

51. Gröttum, K. A., and N. O. Solum. 1969. Congenital thrombocytopenia with giant platelets: a defect in the platelet membrane. $\mathrm{Br}$. $J$. Haematol. 16:277-290.

52. White, J. G., S. M. Burris, D. Hasegawa, and M. Johnson. 1984 Micropipette aspiration of human blood platelets: a defect in BernardSoulier's syndrome. Blood. 63:1249-1252.

53. Jacobson, B. S. 1983. Interaction of the plasma membrane with the cytoskeleton: an overview. Tissue Cell. 15:829-852.

54. George, J. N., A. T. Nurden, and D. R. Phillips. 1984. Molecular defects that cause abnormalities of platelet-vessel wall interactions. $N$. Engl. J. Med. 311:1084-1098. 